\title{
Changes in household well being and resilience: The role of population, family planning and reproductive health in the Tuungane Project
}

Kristen P. Patterson

Follow this and additional works at: https://knowledgecommons.popcouncil.org/departments_sbsr-rh

Part of the Demography, Population, and Ecology Commons, Environmental Public Health Commons, Family, Life Course, and Society Commons, International Public Health Commons, and the Women's Health Commons How does access to this work benefit you? Let us know!

\section{Recommended Citation}

Patterson, Kristen P. 2018. "Changes in household well being and resilience: The role of population, family planning and reproductive health in the Tuungane Project," synopsis. Washington, DC: Population Council, The Evidence Project. 

components of resilience that relate to population, family planning, and reproductive health, from 2011 to 2016. ${ }^{3}$ Informed by these findings, in 2017 an Evidence Project research team, in collaboration with colleagues from multiple organizations involved in the Tuungane Project, conducted additional analyses of the data using structural equation modeling to ascertain and measure the various pathways of resilience, including family planning. An article on the findings of the analyses has been submitted for peer-review and publication.

PHE is a development approach or model characterized by the integration of voluntary family planning (FP), health care, and natural resource management into a single suite of project activities. For example, fisheries management training may also include instruction on hand washing and discussions on the healthy spacing of pregnancies. The PHE approach works on the premise that addressing interrelated challenges through integrated projects can achieve greater overall benefits for both people and the environment than only addressing health or environment separately. Linking family planning to improved health and to protecting the environment may lead to increased contraceptive use and improvements in other development indicators, and enhance community resilience.

\section{FAMILY PLANNING BENEFITS AND POTENTIAL LINKS TO RESILIENCE}

Voluntary FP allows a woman to avoid unintended pregnancy and to time and space births, leading to short- and long-term benefits that can promote resilience. Evidence shows that voluntary FP can lead to better maternal and child health and reduce maternal and child mortality (Singh, Darroch and Ashford 2014). In addition, when a woman spends less time and energy caregiving, she is more likely to continue her education and/ or participate in the labor force or other activities. These outcomes can lead to improved earnings that a woman can use to improve household health, nutrition, and food security, enhancing her household's ability to cope with and bounce back from shocks. Empowering women to exercise their right to choose whether and when to have children increases equity and may be a crucial component of building resilience (Bremner et al 2015).
FIGURE 1. COMPONENTS OF RESILIENCE (PRB, 2018)

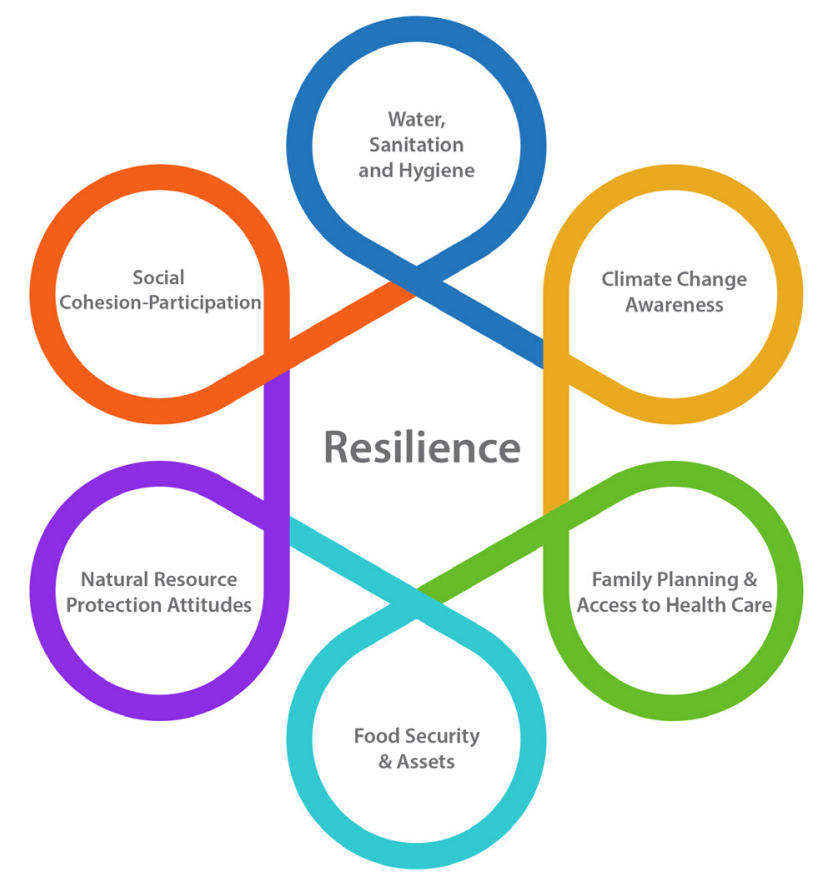

While there is no standard definition of resilience, the United States Agency for International Development (USAID) defines it as "the ability of people, households, communities, countries and systems to mitigate, adapt to and recover from shocks and stresses in a manner that reduces chronic vulnerability and facilitates inclusive growth" (USAID 2012). Efforts to increase resilience involve building the capacity of people and institutions to respond to, address, and recover from challenges, stressors, and economic or environmental shocks.

\section{PHE, Family Planning, and Resilience}

The integrated approach of PHE projects helps build resilience by easing demand for and use of unsustainable practices around natural resources, while simultaneously improving people's health. PHE activities may further support building resilience by increasing and meeting demand for voluntary family planning.

At the population level, increased FP use - supported by equitable access to voluntary FP - can help build resilience by reducing population growth and supporting healthier, more stable family units (Bremner et al. 2015; USAID 2012). This enables communities and governments to better keep pace with the provision of basic social sector services, such as education and health 
MAP 1. TUUNGANE PROJECT AREA (HESS ET AL, 2017)

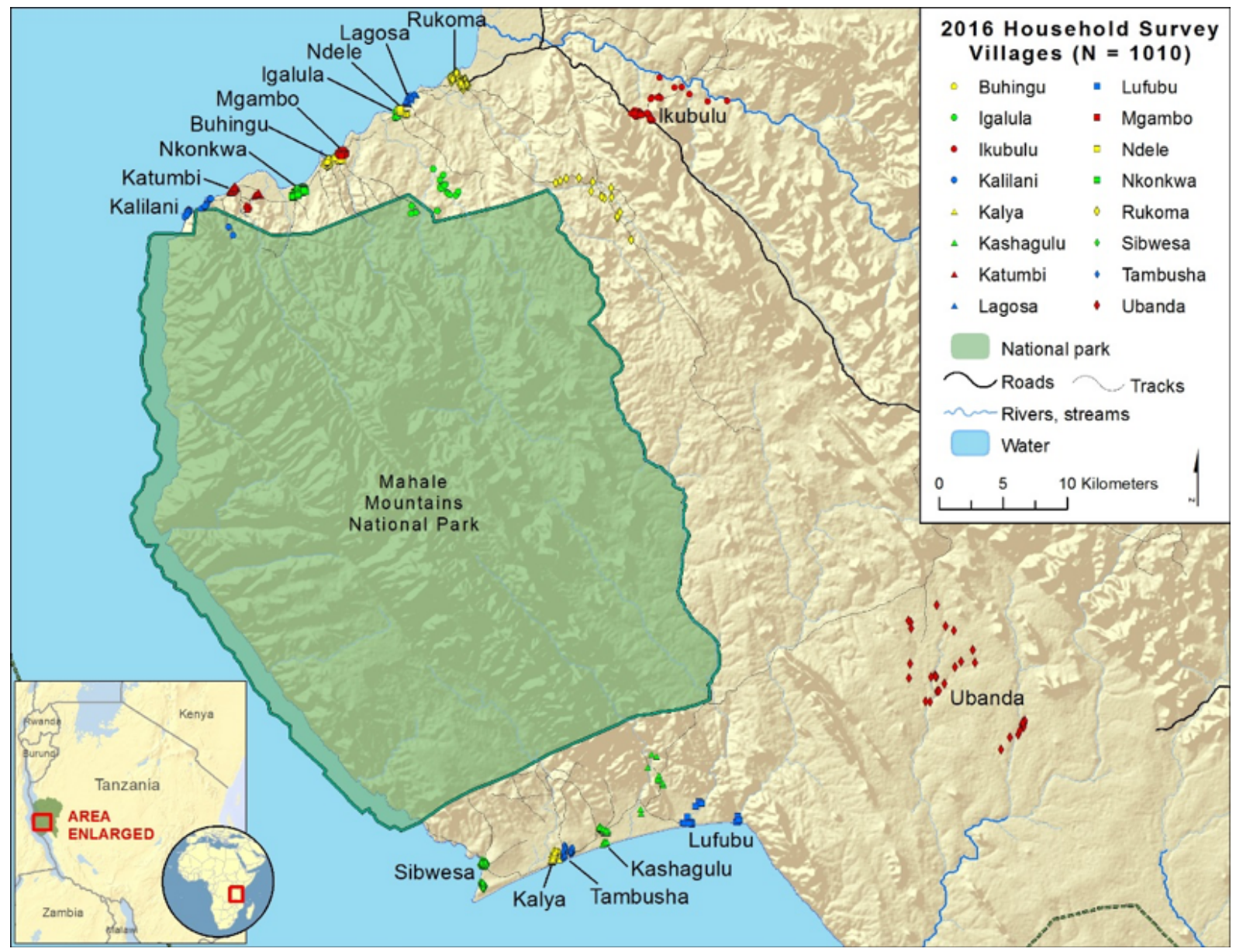

care. Increased use of voluntary FP can also help to ease pressures on the environment associated with rapid population growth (DeSouza 2014; Crist et al. 2017).

The Tuungane Project is one example of a PHE project that has worked to enhance community resilience. Four years into an anticipated long-term program, the Tuungane Project has demonstrated some early successes. Six key components of resilience related to the Tuungane Project activities include: social cohesion-participation; natural resources protection attitudes; food security and assets; water, sanitation, and hygiene; climate change awareness; and family planning and access to health care.

\section{Findings}

The outcome analysis in the Hess report revealed that, four years after the start of Tuungane Project activities, residents of villages in the survey area have better access to family planning, are more able to meet daily needs, and have improved attitudes towards the sustainable use of natural resources. These factors may make households more resilient to shocks and challenges than before their exposure to Tuungane Project activities. Overall, people surveyed said their households were better off in 2016 than five years before. In 2011, 60 percent of respondents said their households had difficulty meeting their daily needs. In 2016, this dropped to 39 percent of households.

\section{Population Knowledge and Perceptions}

In both the 2011 and 2016 surveys, a majority (80 percent and 74 percent, respectively) of respondents believed the village population had increased in the prior five years. When asked what was driving the increase, in 2016 more survey respondents mentioned births than those who mentioned migration. In the 2016 focus group discussions (FGD) and village presentations, however, the dominant perception was that population growth is linked to immigration. Respondents in the household surveys identified several problems related 
to population growth (see Figure 2). In the 2016 qualitative study, positive effects of a larger population were noted, such as economic growth, better social services and infrastructure, and technological innovation. In 2011, 45 percent of respondents didn't feel that population growth was a problem, and even more (60 percent) felt that way in 2016.

\section{Family Planning Knowledge and Perceptions}

Fewer respondents were familiar with family planning in both 2011 (45 percent) and 2016 (59 percent) compared to Tanzanians overall (98 percent of women and 99 percent of men in the 2010 DHS could name at least one FP method). However, a new question in the 2016 survey showed that, after an explanation of FP was given to all respondents, three quarters of them approved of FP. As shown in Figure 3 on the next page, the 2016 survey found that older respondents were less likely to approve of family planning. Among those who disapproved of family planning, the two primary reasons were negative health/side effects (53 percent) and religious reasons (40 percent).

In focus groups, participants often mentioned FP positively within the context of improvements to maternal and child health. Both men and women mentioned that birth spacing improved women's health and allowed women to breastfeed longer. Participants attributed increased wealth to FP, because households had fewer children to feed and women's caregiving responsibilities lessened, allowing them to work and farm more productively.
"We have realized that family planning

has benefits to the community. Tuungane educated us that if we space having children then mothers become healthier and family

income increases. If a woman gives birth every year, it affects her ability to participate in development activities. If this year you're pregnant, then next year you will be rearing a child and fail to go to the farm."

Kalya woman, FGD

"If there is small population, obviously, the land will be enough and environmental conservation will be easier."

Fisherman, FGD

\section{Desired Family Size}

Despite the reduction in child mortality, the total number of children women want remained unchanged from 2011 to 2016, at an average of 7.4. Most of the focus group participants surveyed recognized the economic and environmental benefits of having a smaller family, yet a majority still wanted a large family. Neither housing quality nor a household's ability to meet their daily needs affected the likelihood of wanting a large family in either 2011 or 2016. Although having more than three acres of farming land was positively associated with wanting more than five children in 2011, this association was not found in 2016.

\section{FIGURE 2. PROBLEMS CAUSED BY POPULATION GROWTH (HESS ET AL, 2017)}

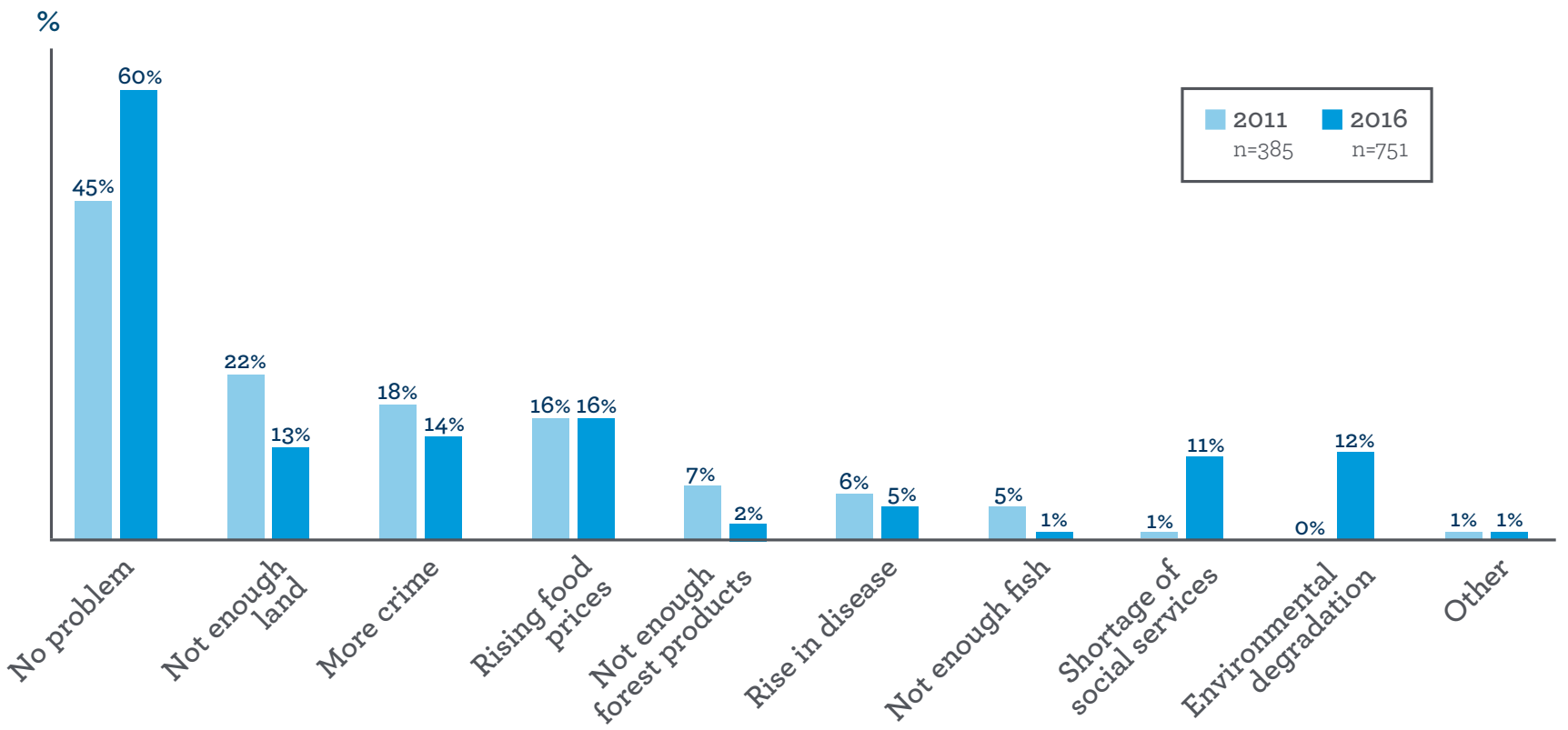


FIGURE 3. APPROVAL OF FAMILY PLANNING BY AGE GROUP, 2016 (HESS ET AL, 2017)

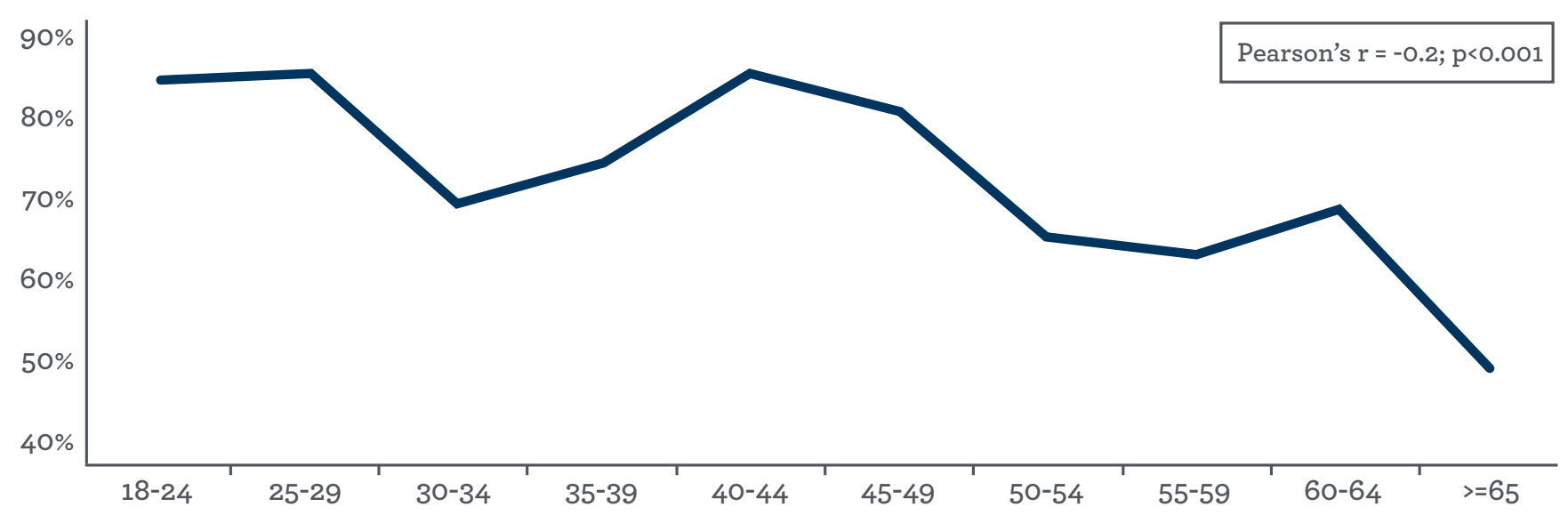

Whether or not respondents thought population growth was problematic did not influence the likelihood of wanting a large family. The traditional cultural desire for large families is underpinned by the need for farm labor, diversification of family incomes, and social safety nets.

In the 2016 survey, respondents were read a list of factors that may influence desired number of children, and were asked which of the factors applied to them; more than 40 percent of respondents selected need for labor, economic resources, and culture/traditions/religion (see Figure 4 on next page).

\section{Reproductive Health}

By 2016, the project had demonstrated modest success in reducing unmet need for FP by increasing knowledge of, access to, and demand for FP. Married women using a modern method of contraception increased from 16 percent in 2011 to 22 percent in 2016. Most of the increase was among women who wanted to space their births, rather than those who wanted to stop childbearing. Half of the women (51 percent) surveyed in 2016 wanted to stop or delay childbearing but were not using any contraception; this is significantly higher than unmet need in the Kigoma Region overall (28 percent) and among other rural Tanzanians (23 percent). Among women not using contraception, reasons shifted slightly from 2011 to 2016: not knowing of any method declined from 15 percent in 2011 to 2 percent in 2016 and husband's or partner's opposition to FP use also declined, while breastfeeding, having no or infrequent sex, and not being married were mentioned more often in 2016 than 2011.

\section{Access to health care}

Over half (56 percent) of survey respondents in 2016 said that access to family planning services had improved over the past five years. Of female respondents who had visited a health facility, the most common services received were for child health (64 percent), antenatal care (14 percent), general treatment (13 percent), family planning (12 percent), and malaria (10 percent). Interestingly, when asked a follow-up question directly about whether they had received a family planning method during their health facility visit, 41 percent of respondents said yes, and of those, nearly all (85 percent) received their desired method.

Focus group participants mentioned that Tuungane helped bring medical clinics to remote sub-villages and eased the shortage of healthcare staff by training local youth to assist them. The Tuungane Project also trained Community-Based Distributors (CBDs) who sensitized women and the community about giving birth at the clinic or hospital, which led to an increase in births with professional health providers such as doctors, nurses, or midwives from 40 percent in 2011 to 49 percent in 2016. The combination of better access to well-equipped local birth facilities and training on safe deliveries through CBDs has decreased infant and child mortality. Focus group discussion participants said information and outreach on pregnancy and childbirth, rehabilitated health clinics, more trained birth attendants, and a boat to transport pregnant women and sick children to the regional hospital helped reduce child mortality. In focus groups, people of various genders and ages frequently mentioned the improvement in health outcomes for women and children as a project benefit. 
FIGURE 4. FACTORS INFLUENCING THE NUMBER OF DESIRED CHILDREN (\% AGREEING WITH INFLUENCE OF EACH FACTOR) (HESS ET AL, 2017)

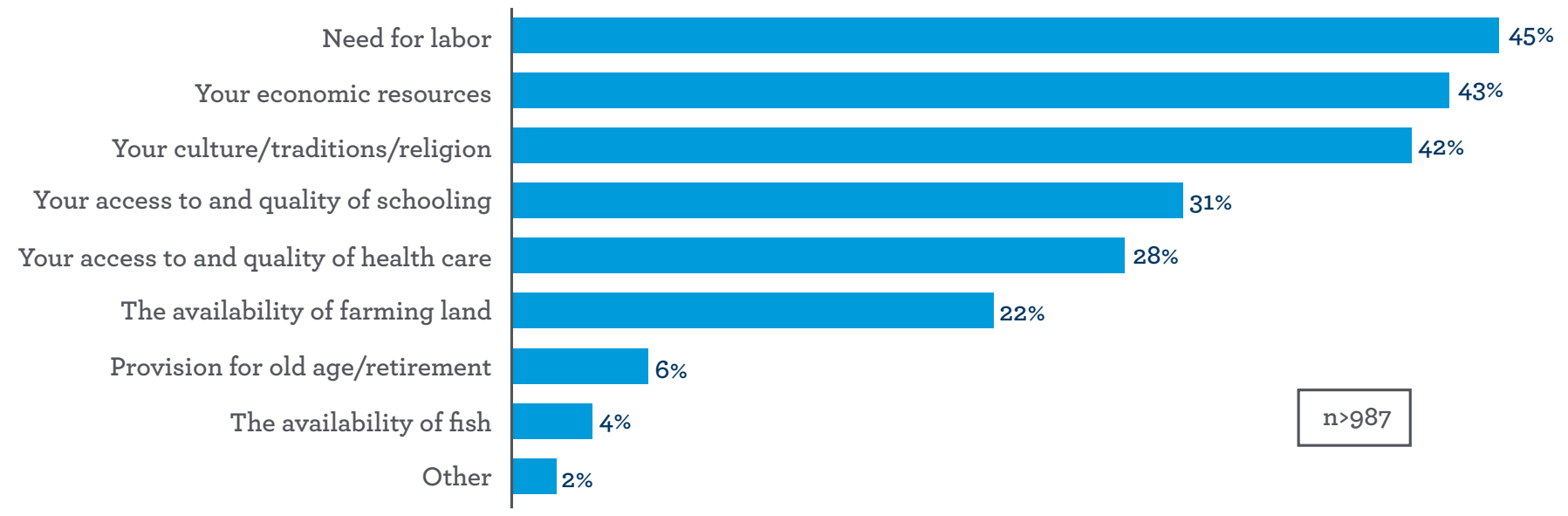

"Family planning education is provided through small groups known as Community Based Distributors (CBDs) to motivate families to use family planning methods and to give birth at the dispensary or hospital."

Mgambo elder, FGD

\section{Other Factors of Resilience}

\section{Social Cohesion}

In the 2016 survey, respondents were asked how much they thought they could trust people in their own village, people in nearby villages, and the local (village and sub-village) government. Respondents generally had more trust in people from their own village than in inhabitants of nearby villages. People trusted their village government more than fellow villagers. The increase in the number of respondents who are open to resolving conflicts through the village government could be a sign of positive changes in social cohesion, which the project identified as a component of resilience.

\section{Access to Credit and Livelihoods}

Diversified livelihoods and funding to support them is a marker of resilience. Most community conservation banking (COCOBA) members are women, so the financial and self-confidence benefits are likely to help their families as well. Family planning often allows women to spend additional time on livelihoods activities; as one woman shared during the FGDs: "Family planning makes a woman healthy and strong. Because she keeps space between one child and another, a woman can engage in other economic activities like business and increase household income" (Kalya elder, FGD).

\section{Natural Resources Management}

In rural areas of western Tanzania, human health and livelihoods are tied closely to the health of their natural environment and the availability of natural resources to provide benefits such as fresh water, food, and shelter. Fishers were less pessimistic in 2016 than in 2011. Those reporting an increase in fish catch compared to five years ago rose from 8 to 33 percent, and the percentage who believed there would not be sufficient fish in the future decreased from 54 in 2011 to 39 in 2016.

Focus group discussion participants said village forests were now better protected and wood harvests better regulated. More people in 2016 thought there was sufficient forest close to their village to meet day-to-day needs. One elder noted the linkages between protecting forests, livelihoods, and population dynamics: "The land becomes insufficient; the amount of farmland remains constant while the number of people increases, and there is an increase in land conflicts. Food becomes scarce because the amount of productive land is too small compared with the population" (Mgambo elder, FGD).

\section{Food Security}

Respondents mostly attributed changes in food security to personal reasons such as illness or increases in household size. The weather and changes in crop health were also cited as reasons for shifts in food security.

\section{Water, Sanitation and Hygiene (WASH)}

WASH activities are a key part of the Tuungane project, and are often cited as contributors to resilience (GOAL 2014; Frankenberger et al. 2013). Focus group participants said improved WASH had reduced cholera 
outbreaks. Changes in access to improved drinking water, whether from public taps, protected private or public wells, and rainwater, were not statistically significant from the 2011 to 2016 surveys, however, 81 percent of households reported having a specific location for members to wash their hands. About half of all households had soap, sand, or ash available at the handwashing place.

\section{Project participant results: population,} family planning, and access to health care

In addition to comparing the overall population between 2011 and 2016, the Hess research team performed analysis on the 2016 data to compare households that participated in project initiatives (Model Households, Beach Management Unit member households, and COCOBA member households) versus those that did not participate. Model Households had better indicators than non-Model Households for attitudes towards conservation, family planning awareness, community participation, and sustainable resource use. Model Households also were more likely to have water ready for washing hands, have soap, sand, or ash available, and use an improved latrine.

A positive attitude towards family planning is part of the Model Household approach. More Model Household respondents identified population growth as problematic, but the ideal number of children between Model and non-Model Households was not statistically

TABLE 1. 2016 MODEL HOUSEHOLD COMPARISON: FAMILY PLANNING AND NATURAL RESOURCE ATTITUDES (HESS ET AL, 2017)

\begin{tabular}{|c|c|c|}
\hline & $\begin{array}{c}\text { Model } \\
\text { Households }\end{array}$ & $\begin{array}{l}\text { Non-model } \\
\text { Households }\end{array}$ \\
\hline \multicolumn{3}{|l|}{ Family Planning ${ }^{4}$} \\
\hline $\begin{array}{l}\text { Respondent believes population growth causes } \\
\text { problems }\end{array}$ & $51 \%$ & $38 \% *$ \\
\hline Respondent's ideal number of children is five or more ${ }^{5}$ & $84 \%$ & $87 \%$ \\
\hline Respondent is aware of family planning & $83 \%$ & $56 \% * *$ \\
\hline Respondent approves of family planning & $80 \%$ & $74 \%$ \\
\hline $\begin{array}{l}\text { Respondent reproductive health section used or using } \\
\text { birth control }\end{array}$ & $47 \%$ & $27 \% * *$ \\
\hline \multicolumn{3}{|l|}{ Natural Resource Attitudes } \\
\hline $\begin{array}{l}\text { Respondent agrees that the village forest should be } \\
\text { conserved }\end{array}$ & $94 \%$ & $87 \% *$ \\
\hline Respondent agrees that wildlife should be protected & $94 \%$ & $88 \% *$ \\
\hline $\begin{array}{l}\text { Respondent agrees that the National Park should stay } \\
\text { protected }\end{array}$ & $95 \%$ & $89 \% *$ \\
\hline Fisher uses ring nets (problematic gear) ${ }^{7}$ & $26 \%$ & $31 \%$ \\
\hline
\end{tabular}

* significant at 5\% level; ** significant at 1\% level different. There is no statistically significant difference between family planning approval levels between Model and non-Model Households; however, the former are more likely to be aware of family planning (83 vs. 56 percent), and to use it (47 vs. 27 percent). It isn't possible to state with certainly that the differences are due to participation in the project, since "positive deviant" households may have been more likely to participate in the model household activities than their peers.

\section{Conclusion}

The outcome analysis of the survey and focus group findings in the Hess report show that after four years, the Tuungane Project has made progress across a number of indicators towards increasing resilience. In summarizing the findings on the population, family planning, and reproductive health components of the project, the Evidence Project researchers conclude these interventions are important to improving household wellbeing, and could be important components of building resilience. Regarding respondents' attitudes to population and family planning, we note that while most people still desire large families, they understand and value family planning for its ability to improve maternal and child health. Results from additional research implemented through the Evidence Project PHE Activity using structural equation modeling will elucidate and measure how family planning and the factors of resilience identified in this work interact with each other and contribute to increasing resilience (Hardee et al., forthcoming). Additional evidence about the correlation between various factors that contribute to resilience should be of interest to the family planning community, the development community and the environmental community alike and can inform future refinements to the Tuungane Project and other PHE projects. 


\section{Project Survey Methodology}

In 2016, in partnership with the Evidence Project, Tuungane conducted a survey of approximately 1,000 households to measure changes since the 2011 project baseline survey. The 2016 follow-on survey included additions to some sections to incorporate an additional focus on resilience to climate change and to assess the pathways through which family planning impacts resilience and other project activities. The additions included questions on hygiene, family planning, climate change, diet and food security, and social cohesion. The reproductive health section was also expanded to allow an evaluation of healthcare facilities and services, and the farming section of the household questionnaire was expanded to better assess current farming practices. Tanzania's National Institute for Medical Research reviewed the survey protocol and granted a clearance certificate for the survey. In addition to this five-year follow-on survey, the Evidence Project and others supported qualitative data collection via FGDs with community members.

The results of the survey and FGDs were synthesized in a report titled "Changes in Household Well-Being and Resilience 20112016," which documents a repeat cross-sectional survey of 10 villages in the project area, and explains the changes found between the July 2011 baseline survey and the August 2016 follow-on survey (Hess et al. 2017). This synopsis summarizes key findings from that report related to family planning and other resilience components.

\section{REFERENCES}

Jason Bremner, Kristen P. Patterson, and Rachel Yavinsky, “Building Resilience Through Family Planning: A Transformative Approach for Women, Families, and Communities," (August 2015), accessed at www.prb.org/ pdf15/sahel-resilience-brief.pdf

Crist, Eileen, Camilo Mora, and Robert Engelman. 2017. The interaction of human population, food production, and biodiversity protection. Science 21 Apr 2017: Vol. 356, Issue 6335, pp. 260-264. DOI: 10.1126/science. aal2011.

DeSouza, Roger-Mark. 2014. Resilience, integrated development and family planning: building long-term solutions. Reprod Health Matters. 2014 May;22(43):75-83. doi: 10.1016/S0968-8080(14)43773-X.

Frankenberger, T. et al. 2013. Community Resilience: Conceptual Framework and Measurement Feed the Future Learning Agenda. October. Rockville, MD: Westat.

GOAL. 2014. “Toolkit for Measuring Community Disaster Resilience: Guidance Manual." Accessed at https://www.goalglobal.org/images/GOAL Toolkit_Disaster_Resilience_Guidance Manual_May 2015.compressed. pdf.
Hardee, Karen et al., forthcoming. "How Does Taking an Integrated Population, Health, and Environment Approach Contribute to Increased Resilience to Climate Change?" Under review.

Hess, Sebastiaan et al. 2017. "Changes in Household Well-Being and Resilience 2011-2016." Accessed at http://evidenceproject.popcouncil. org/resource/changes-in-household-well-being-and-resilience-2011-2016tuungane-project-tanzania/

Singh, Susheela, Jaqueline E. Darroch, and Lori S. Ashford. 2014. "Adding it Up: The Costs and Benefits of Investing in Sexual and Reproductive Health 2014," accessed at https://www.guttmacher.org/sites/default/files/report pdf/addingitup2014.pdf

United States Agency for International Development (USAID). 2012. "Building Resilience to Recurrent Crisis." December. Accessed at https://www.usaid. gov/sites/default/files/documents/1870/USAIDResiliencePolicyGuidanceDocument.pdf

Yavinsky, Rachel Winnik et al. 2015. "The Impact of Population, Health, and Environment Projects: A Synthesis of Evidence,” Working paper. Accessed at http://evidenceproject.popcouncil.org/wp-content/uploads/2015/06/ PHE-Synthesis-Report1.pdf.

\section{ENDNOTES}

1 The Tuungane Project is a collaboration between The Nature Conservancy and Pathfinder International. Other project stakeholders include local governments, Frankfurt Zoological Society, the Jane Goodall Institute, Tanzania National Parks, Tongwe Trust, and the Government of Tanzania. 2 The baseline

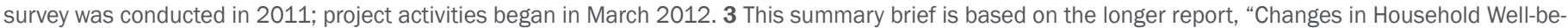

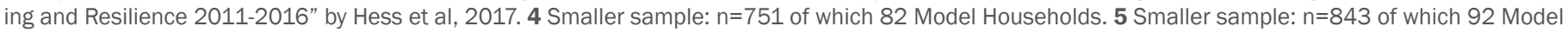
Households. 6 Smaller sample: $n=740$ of which 70 Model Households. 7 Smaller sample: $n=180$ of which 23 Model Households.

\section{ACKNOWLEDGMENTS}

The author would like to thank Smita Gaith, Elizabeth Gay, Kate Gilles, Robin Johnson, Anneka Van Scoyoc, and Jessica Woodin of PRB for their key inputs and edits; Karen Hardee of the Evidence Project for her guidance; and Clive Mutunga of USAID for his contributions. In addition, special thanks go to Craig Leisher of The Nature Conservancy, Sebastiaan Hess, and their fellow co-authors for creating the full report from which this brief is drawn; the enumerators who gathered the data; and, of course, the people in the Tuungane Project area, without whom this work would not be possible.

THE EVIDENCE PROJECT

Population Council 4301 Connecticut Avenue NW Suite 280

Washington, DC 20008 USA tel +12022379400 evidenceproject@popcouncil.org

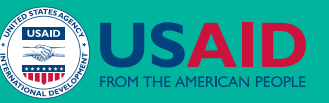

The Evidence Project is made possible by the generous support of the American people through the United States Agency for International Development (USAID) under the terms of cooperative agreement no. AID-OAA-A-13-00087. The contents of this document are the sole responsibility of the Evidence Project and Population Council and do not necessarily reflect the views of USAID or the United States Government.

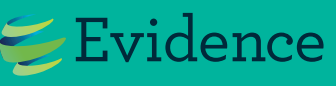

The Evidence Project uses implementation science--the strategic generation, translation, and use of evidence-to strengthen and scale up family planning and reproductive health programs to reduce unintended pregnancies worldwide. The Evidence Project is led by the Population Council in partnership with INDEPTH Network, International Planned Parenthood Federation, Management Sciences for Health, PATH, Population Reference Bureau, and a University Research Network.

Suggested Citation: Patterson, Kristen P. 2018. "Changes in Household Well Being and Resilience: The Role of Population, Family Planning and Reproductive Health in the Tuungane Project," Synopsis. Washington, DC: Population Council, The Evidence Project. 